\title{
Perspectives
}

\section{Toward a transdisciplinary understanding and a global control of emerging infectious diseases}

\author{
Jean-Paul Gonzalez ${ }^{1}$, Gérard Lambert ${ }^{2}$, Anaïs Legand ${ }^{3}$, Patrice Debré ${ }^{3}$ \\ ${ }^{1}$ Centre International de Recherches Médicales de Franceville (CIRMF), Gabon \\ ${ }^{2}$ Centre Cavaillès, Ecole Normale Supérieure, Paris, France \\ ${ }^{3}$ Ministry of Foreign and European Affairs, Paris, France
}

\begin{abstract}
The Franceville International Centre for Medical Research (CIRMF) organized a first international symposium on infectious diseases, environments, and biodiversity. Over 200 international experts gathered in Gabon to forecast and work to prevent the emergence of infectious diseases.

This symposium aimed to strengthen the regional and international fight against the emergence of infectious diseases with high-level scientific debates. Toward this goal, it brought together experts in human and animal health, the environment, and ecology, including biologists, climatologists, microbiologists, epidemiologists, public health professionals, and human and social sciences specialists.

National, regional and international participants were present to debate on the challenges related to the emergence of infectious diseases and on the responses to be implemented.

The symposium was very successful, and plans for a second symposium of this kind to be held in the near future in another high-biodiversity area are already underway.
\end{abstract}

Key words: international symposium; emerging diseases; surveillance and research centres; transdisciplinary approach

J Infect Dev Ctries 2011; 5(12):903-905.

(Received 23 November 2011 - Accepted 05 December 2011)

Copyright (C) 2011 Gonzalez et al. This is an open-access article distributed under the Creative Commons Attribution License, which permits unrestricted use, distribution, and reproduction in any medium, provided the original work is properly cited.

\section{Post symposium summary}

The First Symposium on Emerging Infectious Diseases, Biodiversity and the Environment held in Libreville, Gabon, took place 4 and 5 November 2011, at the French Institute of Gabon.

The symposium, conducted under the high patronage of the Gabonese Head of State, was hosted by the Centre International de Recherches Médicales de Franceville (CIRMF, Gabon; http://www.cirmf.org/), and sponsored by the State of Gabon, the TOTAL Foundation, the TOTAL-Gabon oil company, the "Institut Français du Gabon" (IFG, Libreville), and the French Ministry of Foreign and European Affairs.

Over 200 participants from all over the world attended the opening day in an innovative and transdisciplinary approach to gain a better understanding of the emergence of infectious diseases (Figure1).
The symposium aimed to

- Promote the efforts of all involved stakeholders to communicate and enhance scientific debates

- Advocate for transdisciplinary and global answers to face emerging infectious diseases

- Foster debates for future actions on the scientific level as well as on the political level to develop and support innovative policies on emerging infectious diseases

- Encourage partnerships (i.e., public-private, developed/developing countries, "North/South" surveillance-research programs) to gather all disciplinary fields involved in survey and research on emerging infectious diseases

To look holistically at the emergence of infectious diseases, the symposium focused on the following topics:

- Factors in the emergence of infectious diseases

- Conservative medicine and zoonotic risks 
Figure 1. Congress attendance

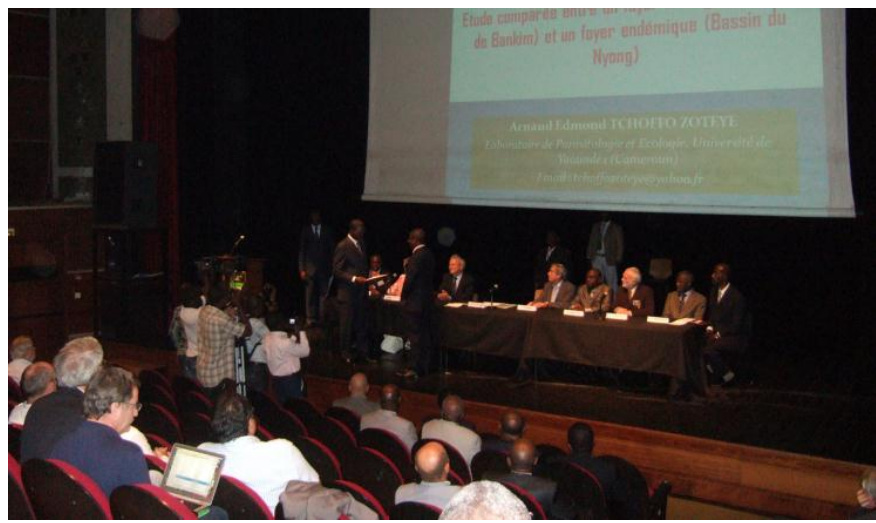

- Vector-borne diseases, hemorrhagic fevers, severe neurological and gastro-enteritis syndromes

- Natural hosts, vectors and reservoirs, and their environments

- Strategies assessment to address risks of emergence

- Tools and techniques for the monitoring, controlling, and surveillance of emerging infectious diseases

Furthermore, at the political level, the potential implementation and roles of research centres, as well as the development of networks and tools for surveillance were enhanced while surveillance and research strategies aimed at the animal-humanecosystems interface were emphasized.

One of the highlights of the occasion was the presentation of an award to a young African researcher from Cameroon, M. Arnaud Tchoffo Zoteye, for the best junior African study on an emerging or remerging phenomenon. The "Ali Bongo Ondimba" award was presented by Professor Françoise BarréSinoussi, Nobel Prize in Medicine laureate. The prize was delivered on behalf of the Gabonese government by the Minister in charge of Research for Gabon, M. Séraphin Mondounga (Figure 2).

Four sessions debating the following topics were held during the symposium:

- The emergence of infectious diseases in a global perspective

- Emerging diseases and environments: emergence in relation to human activities; dynamics of emergence, evolution, ecosystem changes, and their impacts
- Biodiversity and pathogens tracking: tools, techniques and strategies for research and health surveillance at microbiological, epidemiological and global scales

- Public health, the care system, and health networks today and tomorrow

A roundtable discussion, aimed at forecasting "international, regional and national perspectives on how to deal with emerging infectious diseases" brought the sessions to a close.

Concluding remarks on the symposium were given by the scientific committee and presented by Minister Moudounga, who noted the following highlights:

- The need to track down pathogens in areas of high biodiversity (i.e., "hot spots") to evaluate the zoonotic risk associated with wild animals. Tracking and forecasting appear to be the main missions already developed by several centres and teams, including the CIRMF, the Centre de Recherche et de Veille sur les maladies émergentes dans l'Océan Indien (CRVOI), the Global Virus Forecasting Initiative (GVFI), and the United States Agency for International Development (USAID) through their "PREDICT" project and research activities. They all support programs relevant to the inter-tropical zone of Africa, Asia, and the Indian Ocean.

Figure 2. (left to right) Professor Françoise BARRE-SINOUSSI, researcher at the Pasteur Institute, Nobel Prize in Medicine recipient in 2008 for the discovery of HIV, and scientific advisor for the Total Foundation; Dr. Arnauld Edmond TCHOFFO ZOTEYE, winner of the Ali Bongo Ondimba award, researcher with the Parasitology and Ecology Laboratory at the University of Yaounde.

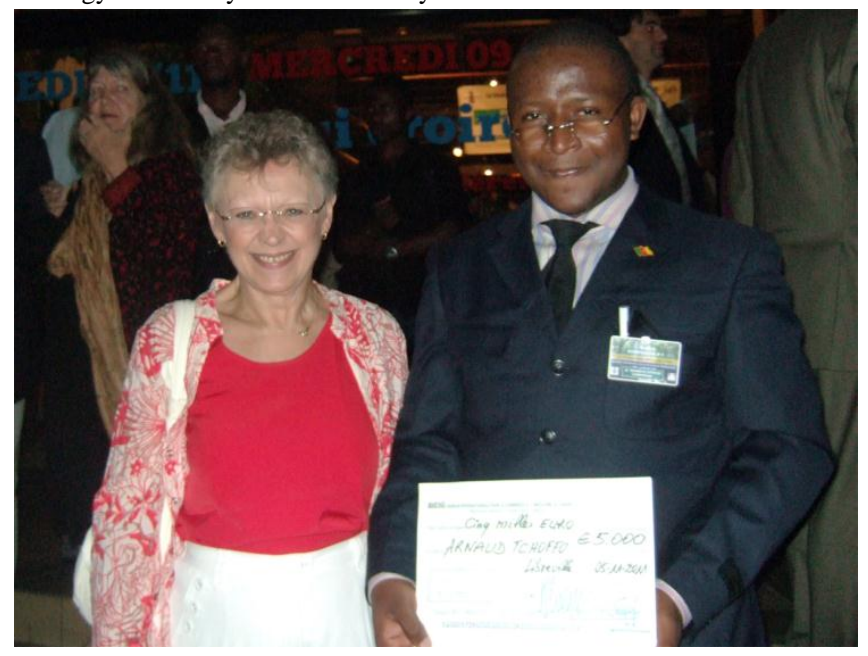


- The need for health surveillance closely associated with research to obtain and use, by the fastest and most efficient possible means, the results of the detection and control of emerging or reemerging infectious diseases/agents

- An international partnership for the public and private sectors that will also increase the potential for detecting and evaluating the risk and its control

- The requirement for promoting transdisciplinary approaches for surveillance and research centres and/or networks and also for organizing academic training for such an innovative method dedicated to a better understanding of disease emergence

Ultimately, the First Symposium on Emerging Infectious Diseases, Biodiversity, and the
Environment was set to promote interdisciplinary teams and transdisciplinary surveillance and research projects, as well as the deregulation of disciplines including health sciences at large, biological sciences, environmental sciences and human and social sciences.

Enthusiastic about this first meeting and its outcome, the participants are now planning a second edition of this symposium.

\section{Corresponding author}

Anaïs Laure Legand

Ministry of Foreign Affairs

France

Conflict of interests: No conflict of interests is declared. 